\title{
Introduction of a New Policy of no Nighttime Appendectomies: Impact on Appendiceal Perforation Rates and Postoperative Morbidity
}

\author{
Beat Schnüriger · Jessica Laue • Dino Kröll • \\ Daniel Inderbitzin • Christian A. Seiler • \\ Daniel Candinas
}

Published online: 26 November 2013

(C) Société Internationale de Chirurgie 2013

\begin{abstract}
Background Working hour limitations and tight health care budgets have posed significant challenges to emergency surgical services. Since 1 January 2010, surgical interventions at Berne University Hospital between 23:00 and 08:00 $\mathrm{h}$ have been restricted to patients with an expected serious adverse outcome if not operated on within $6 \mathrm{~h}$. This study was designed to assess the safety of this new policy that restricts nighttime appendectomies (AEs). Methods The patients that underwent AE from 1 January 2010 to 31 December 2011 ("2010-2011 group") were compared retrospectively with patients that underwent $\mathrm{AE}$ before introduction of the new policy (1 January 2006-31 December 2009; "2006-2009 group”).

Results Overall, 390 patients were analyzed. There were 255 patients in the 2006-2009 group and 135 patients in the 2010-2011 group. Patients' demographics did not differ statistically between the two study groups; however, $45.9 \%$ of the 2006-2009 group and $18.5 \%$ of the 2010-2011 group were operated between 23:00 and 08:00 h $(p<0.001)$. The rates of appendiceal perforations and surgical site infections did not differ statistically between the 2006-2009 group and the 2010-2011 group (20 vs. $18.5 \%, p=0.725$ and 2 vs. $0 \%, p=0.102$ ). Additionally, no difference was found for the hospital length of stay ( $3.9 \pm 7.4$ vs. $3.4 \pm 6.0$ days, $p=0.586)$. However, the proportion of patients with an in-hospital
\end{abstract}

Oral presentation at the 99th Annual Meeting of the Swiss Society of Surgery, 2012, Davos, Switzerland.

B. Schnüriger $(\bowtie) \cdot$ J. Laue · D. Kröll · D. Inderbitzin

C. A. Seiler - D. Candinas

Department of Visceral Surgery and Medicine, Bern University

Hospital, 3010 Bern, Switzerland

e-mail: beat.schnuriger@gmail.com delay of $>12$ h was significantly greater in the 2010-2011 group than in the 2006-2009 group [55.6 vs. 43.5\%, $p=0.024$, odds ratio (95\% confidence interval 1.62 (1.1-2.47)].

Conclusions Restricting AEs from 23:00 to 08:00 h does not increase the perforation rates and occurrence of clinical outcomes. Therefore, these results suggest that appendicitis may be managed safely in a semielective manner.

\section{Introduction}

Increasing working hour limitations and tight health care budgets have posed significant challenges to emergency surgical services. Appendicitis is one of the most common surgical emergencies. If we could safely manage this disease in a semielective manner, as proposed by other investigators [1-4], resource utilization would be optimized.

The association between the delay to appendectomy (AE) with outcomes in patients admitted with acute appendicitis is highly controversial. Increasing rates of appendiceal perforation and surgical site infections have been associated with a longer delay to AE [5-7]. In contrast, a large number of studies have found a relationship between perforation and the prehospital delay, whereas no association with the in-hospital delay was found $[6,8-11]$. These results suggest that the majority of perforations occur before the patients arrive at the hospital.

At Bern University Hospital, surgical interventions between 23:00 and 08:00 h have been restricted since 1 January 2010 to patients in a critical state of health and with an expected serious adverse outcome if not operated on within $6 \mathrm{~h}$. Due to the highly questionable association between the delay to AE with outcomes, this new rule also was applied to patients admitted with suspected acute 
appendicitis. We opted to assess the safety of this new policy in patients admitted with acute appendicitis and to examine its impact on the in-hospital delay to AE.

\section{Methods}

After Institutional Review Board approval (IRB number 12-007), the prospectively entered operation registry of the Department of Visceral and Transplant Surgery at Berne University Hospital, Switzerland, was queried for patients who underwent AE from 1 January 2006 to 31 December 2011. Berne University Hospital is a tertiary academic center providing a 24-h surgical service. There is a surgical team on call during the day (8:00 and 18:00 $\mathrm{h}$ ) and another team at night $(18: 00$ and 08:00 h). There are anesthesia teams and operating room (OR) personnel in-house available at any time. Generally, AEs are performed by residents under the supervision of an attending abdominal surgeon. At nighttime, there are two ORs dedicated to emergency cases available. These two ORs are shared between abdominal, cardiothoracic, neurosurgical, and orthopedic emergencies. Every case is prioritized by the responsible surgeon (Priority 1 immediate operation required, Priority 2 operation required within 6 h, Priority 3 operation required within 6-12 h, Priority 4 operation required within 12-24 h). This standardized prioritization subsequently defined the sequence of procedures.

The patients' data were collected retrospectively using a computerized spreadsheet (Microsoft Excel 2003, Microsoft Corporation, Redmond, WA) and included demographics on hospital admission, in-hospital delay from emergency room (ER) admission to $\mathrm{AE}$, and clinical data. The collected demographic variables were age, gender, diabetes mellitus, smoking history, steroid therapy, American Society of Anesthesiologists (ASAs) physical status classification, C-reactive protein (CRP), and white blood cell (WBC) count at admission and prehospital duration of abdominal pain. The presence of appendiceal perforation was queried from the written pathological report of the surgical specimen.

The ER admission times were captured from the electronic patient management system in which patient entries to the ER suite are routinely documented by the ER nurses $\left(4 \mathrm{dClient}{ }^{\circledR}\right.$, version 6.8, 4D S.A., San Jose, CA). In addition, the time of notification of the OR personnel (including the anesthesiologists) by the responsible surgeon was obtained from the institutional electronic OR registration system that systematically records the time of all patient entries. Finally, operation times were queried from the electronic patient management system, where incision times are documented routinely by the OR personnel
(Polypoint $^{\circledR}$ RAP DIS DOC, version g2.6.3, Erne Consulting AG, Gümligen, Berne, Switzerland).

Since 1 January 2010, surgical interventions between 23:00 and 08:00 $\mathrm{h}$ have been restricted to patients in a critical state of health and with an expected serious adverse outcome if not operated within $6 \mathrm{~h}$. Patients with suspected appendicitis were defined as having a noncritical health condition and were prioritized as requiring operation within $12 \mathrm{~h}$ (Priority 4). Patients with suspected acute appendicitis who were not operated on until 23:00 h could be postponed to the next day at the discretion of the responsible attending surgeon. These deferred patients were prioritized the following morning (at 08:00 h) as requiring operation within $6 \mathrm{~h}$. Patients who underwent $\mathrm{AE}$ before introduction of this new policy were defined as the "2006-2009 group." Those who fell within the new rule were defined as the "2010-2011 group."

Preoperative diagnostic measures routinely included clinical examination, laboratory parameters (including CRP level, WBC count), and abdominal ultrasonography. Due to ethical concerns, the decision and timing of surgical intervention was always at the discretion of the attending surgeon. All patients received i.v. antibiotic prophylaxis with amoxicillin/clavulanic acid, ciprofloxacin/metronidazole or piperacillin/tazobactam until surgical intervention. This regimen of prophylactic antibiotic therapy before surgery was applied during the entire study period.

Firstly, in order to detect potential risk factors for appendiceal perforation, patient characteristics, including in-hospital delay to operation, were compared between the perforated and the nonperforated group using univariate analysis. Subsequently, all differences $(p \leq 0.2)$ were entered into a forward logistic regression model to identify independent risk factors for appendiceal perforation. The in-hospital delay was forced into the equation of this regression model.

Secondly, the 2006-2009 group and the 2010-2011 group were compared to assess the impact and safety of the new policy of "no nighttime appendectomy" on the patients' clinical outcomes and in-hospital delay to AE. Primary outcome measures included the rate of appendiceal perforation, infectious complications (wound infections/fascial dehiscence and abdominal infectious complications or abscesses), postoperative ileus (no stool passed for $>3$ days after surgery), and hospital length of stay (HLOS). Secondary outcome measures included the in-hospital delay from $\mathrm{ER}$ admission to $\mathrm{AE}, \mathrm{ER}$ admission to notification of OR personnel by the responsible surgeon, and the delay from notification of OR personnel to AE. In addition, the in-hospital delay was compared between the two study groups stratified according to the ER admission time. 
Continuous variables, times, and categorical variables are reported as mean \pm standard deviation (SD), median (range), and percentages, respectively. $p$ values were obtained from the $\chi^{2}$ test for proportions or Student's $t$ test for continuous variables. Mann-Whitney $U$ test was used to compare not normally distributed data. All statistical analysis were performed using the Statistical Package for Social Sciences (SPSS Windows (C)), version 17.0 (SPSS Inc., Chicago, IL).

\section{Results}

During the 6-year study period, 390 patients were admitted with the diagnosis of acute appendicitis and subsequently underwent $\mathrm{AE}$. The overall mean age was $35.7 \pm 16.2$ years and $52.8 \%(N=206)$ were male patients (Table 1$)$. The mean duration of prehospital abdominal pain was $38.4 \pm 53.4 \mathrm{~h}$. The mean CRP level and WBC count on admission were $65.2 \pm 76.7 \mathrm{mg} / \mathrm{L}$ and $12.6 \pm 4.7 \times 10^{3} / \mathrm{L}$, respectively. Overall, $98.2 \%(N=383)$ of AEs were performed laparoscopically, with a conversion rate of $5.6 \%$ $(N=22)$. The mean delay from ER admission to AE was $15.2 \pm 12.9 \mathrm{~h}$. The mean time from ER admission to notification of the OR team by the responsible surgeon was $8.1 \pm 10.5 \mathrm{~h}$, and the time from notification of the OR team to AE was $7.3 \pm 8.3 \mathrm{~h}$ (Table 1 ). Overall, the negative AE rate was $5.4 \%(N=21)$.

The overall rate of perforated appendicitis was $19.5 \%$ $(N=76)$. Patients with appendiceal perforation had significantly more wound infections/fascial dehiscences and abdominal abscesses than the nonperforated group (5.3 vs. $0.3 \%, p=0.001$, and 3.9 vs. $0.6 \%, p=0.021)$. Univariate analysis revealed that patients with appendiceal perforation were older, had a longer prehospital history of abdominal pain, had higher CRP levels and WBC counts on admission, and had an increased ASA physical status classification (Table 1). However, the distribution of inhospital delays was similar in the perforated and nonperforated groups. Forward logistic regression analysis revealed the following independent risk factors for perforation [odds ratio $(95 \% \mathrm{CI})]$ : increasing CRP level [1.01 (1.01-1.02), $p<0.001]$, older age [1.03 (1.01-1.06), $p=0.001]$, longer prehospital duration of abdominal pain [1.01 (1.00-1.01), $p=0.012]$, and increasing WBC count [1.07 (1.00-1.15), $p=0.049]$ (total $R^{2}=0.372$ ).

There were 255 patients in the 2006-2009 group and 135 patients in the 2010-2011 group. Table 2 presents detailed overall patient characteristics and comparison between these two study groups. The demographics compared did not show any statistical significant differences. However, the proportion of patients who underwent $\mathrm{AE}$ during the night (between 23:00 and 08:00 h) differed significantly between the two groups (45.9 vs. $18.5 \%$, $p<0.001$; Table 2). Before introduction of the new guidelines, the number of AEs peaked shortly after midnight. After introduction of the new policy, the AEs shifted towards the late afternoon.

The clinical outcomes, including perforation rate and infectious complications, were similar in the 2006-2009 and the 2010-2011 groups (Table 3). However, in contrast to the 2006-2009 group, the 2010-2011 group showed a bimodal distribution of the delay from ER admission to AE with a second peak between 12 and $18 \mathrm{~h}$. This resulted in a significantly greater proportion of patients with an overall in-hospital delay of 12-24 $\mathrm{h}$ for the 2010-2011 group than the 2006-2009 group (37.8 vs. $24.7 \%, p=0.007$, odds ratio [95 \% CI] 1.85 [1.18-2.9]; Fig. 1). The proportion of
Table 1 Overall patient characteristics and comparison between nonperforated and perforated groups

\footnotetext{
* Student's $t$ test, $\chi^{2}$ test;

** variables put into the equation of the forward logistic regression model

$C R P$ C-reactive protein, $W B C$ white blood cell, ASA American Society of Anesthesiologists, $A E$ appendectomy, $E R$ emergency room, $O R$ operating room
}

\begin{tabular}{|c|c|c|c|c|}
\hline & $\begin{array}{l}\text { Total } \\
(N=390)\end{array}$ & $\begin{array}{l}\text { Nonperforated } \\
(N=314)\end{array}$ & $\begin{array}{l}\text { Perforated } \\
(N=76)\end{array}$ & $p$ value* \\
\hline Age, mean \pm SD (years) & $35.7 \pm 16.2$ & $33.9 \pm 14.9$ & $43.2 \pm 19$ & $<0.001 * *$ \\
\hline Male $[\%(n)]$ & $52.8(206)$ & $52.5(165)$ & $53.9(41)$ & 0.826 \\
\hline Smoker $[\%(n)]$ & $10.5(41)$ & $9.9(31)$ & $13.2(10)$ & 0.402 \\
\hline Diabetes mellitus $[\%(n)]$ & $2.6(10)$ & $2.2(7)$ & $3.9(3)$ & 0.395 \\
\hline History of steroid intake $[\%(n)]$ & $5.1(20)$ & $4.5(14)$ & $7.9(6)$ & 0.223 \\
\hline Admission CRP level, mean $\pm \mathrm{SD}(\mathrm{mg} / \mathrm{dL})$ & $65.2 \pm 76.7$ & $49.5 \pm 61.2$ & $128.6 \pm 98.2$ & $<0.001 * *$ \\
\hline Admission WBC count, mean $\pm \mathrm{SD}(\mathrm{G} / \mathrm{L})$ & $12.6 \pm 4.7$ & $12.3 \pm 4.5$ & $13.8 \pm 5.1$ & $0.028 * *$ \\
\hline ASA physical status classification, mean $\pm \mathrm{SD}$ & $1.8 \pm 0.7$ & $1.7 \pm 0.6$ & $2.1 \pm 0.7$ & $<0.001 * *$ \\
\hline Prehospital duration of pain, mean $\pm \mathrm{SD}$ (h) & $38.4 \pm 53.4$ & $29.6 \pm 31.3$ & $73.7 \pm 94.5$ & $<0.001 * *$ \\
\hline Laparoscopic AE $[\%(n)]$ & $98.2(383)$ & $98.7(310)$ & $96.1(73)$ & 0.115 \\
\hline Conversion laparoscopic to open $\mathrm{AE}[\%(n)]$ & $5.6(22)$ & $3.8(12)$ & $13.2(10)$ & 0.002 \\
\hline Admission to $\mathrm{AE}(\mathrm{h})$ & $15.2 \pm 12.9$ & $15.5 \pm 13.5$ & $14.1 \pm 9.8$ & $0.406 * *$ \\
\hline Admission to notification of OR (h) & $8.1 \pm 10.5$ & $8.4 \pm 11.3$ & $6.5 \pm 5.5$ & $0.213 * *$ \\
\hline Notification of OR to AE (h) & $7.3 \pm 8.3$ & $7.2 \pm 8.4$ & $7.5 \pm 8.0$ & $0.777 * *$ \\
\hline
\end{tabular}


Table 2 Comparison of the demographics and in-hospital delay of the 2006-2009 and 2010-2011 groups

\begin{tabular}{|c|c|c|c|}
\hline & $\begin{array}{l}2006-2009 \\
\text { group } \\
(N=255)\end{array}$ & $\begin{array}{l}2010-2011 \\
\text { group } \\
(N=135)\end{array}$ & $p$ value* \\
\hline $\begin{array}{l}\text { AE between } 23: 00 \text { and } \\
08: 00 \mathrm{~h}[\%(n)]\end{array}$ & 45.9 (117) & $18.5(25)$ & $<0.001$ \\
\hline Age, mean \pm SD (years) & $35.3 \pm 16$ & $36.6 \pm 16.5$ & 0.47 \\
\hline Male $[\%(n)]$ & $50.6(129)$ & $57(77)$ & 0.225 \\
\hline Smoker $[\%(n)]$ & $9.8(25)$ & $11.9(16)$ & 0.530 \\
\hline Diabetes mellitus [\% $(n)]$ & $2.4(6)$ & $3(4)$ & 0.717 \\
\hline $\begin{array}{l}\text { History of steroid intake } \\
{[\%(n)]}\end{array}$ & $5.1(13)$ & $5.2(7)$ & 0.970 \\
\hline $\begin{array}{l}\text { Admission CRP level, } \\
\text { mean } \pm \mathrm{SD}(\mathrm{mg} / \mathrm{dL})\end{array}$ & $68.5 \pm 81.2$ & $60.4 \pm 69.9$ & 0.360 \\
\hline $\begin{array}{l}\text { Admission WBC count, } \\
\text { mean } \pm \mathrm{SD}(\mathrm{G} / \mathrm{L})\end{array}$ & $12.9 \pm 4.8$ & $12.3 \pm 4.4$ & 0.248 \\
\hline $\begin{array}{l}\text { ASA physical status } \\
\text { classification, } \\
\text { mean } \pm S D\end{array}$ & $1.8 \pm 0.7$ & $1.7 \pm 0.7$ & 0.389 \\
\hline $\begin{array}{r}\text { Prehospital duration of } \\
\text { pain, mean } \pm \text { SD }(h)\end{array}$ & $39.4 \pm 55.3$ & $36.4 \pm 49.8$ & 0.610 \\
\hline $\begin{array}{l}\text { Attempted laparoscopic } \\
\text { AE }[\%(n)]\end{array}$ & $97.6(249)$ & $99.3(134)$ & 0.241 \\
\hline $\begin{array}{l}\text { Conversion laparoscopic } \\
\text { to open } \mathrm{AE}[\%(n)]\end{array}$ & $4.7(12)$ & $7.4(10)$ & 0.271 \\
\hline $\begin{array}{l}\text { Admission to AE (h), } \\
\text { median (range) }\end{array}$ & $\begin{array}{l}10.7 \\
(0.8-114.8)\end{array}$ & $\begin{array}{l}13.4 \\
(1.7-70.4)\end{array}$ & $0.330 * *$ \\
\hline $\begin{array}{l}\text { Admission to notification } \\
\text { of OR (h), median } \\
\text { (range) }\end{array}$ & $\begin{array}{l}4.9 \\
\quad(0.5-105.2)\end{array}$ & $\begin{array}{l}5.2 \\
\quad(0.3-30.7)\end{array}$ & $0.777 * *$ \\
\hline $\begin{array}{l}\text { Notification of OR to } A E \\
\text { (h), median (range) }\end{array}$ & $\begin{array}{l}3.6 \\
(0.5-51.3)\end{array}$ & $5(0.5-33.6)$ & $0.042 * *$ \\
\hline
\end{tabular}

$C R P$ C-reactive protein, $W B C$ white blood cell, ASA American Society of Anesthesiologists, $A E$ appendectomy, $E R$ emergency room, $O R$ operating room

* Student's $t$ test, $\chi^{2}$ test; ** Mann-Whitney $U$ test

patients with an overall in-hospital delay of $>36 \mathrm{~h}$ was similar between the 2010-2011 group and the 2006-2009 group $[3.7 \%(5 / 135)$ vs. $5.9 \%(15 / 255), p=0.353$, odds ratio $(95 \% \mathrm{CI}) 0.615(0.22-1.73)$; Fig. 1]. Due to the bimodal distribution of the delay to AE of the 2010-2011 group further analysis was performed using medians (range) and Mann-Whitney $U$ test. It was found that the overall median time from ER admission to $\mathrm{AE}$ and $\mathrm{ER}$ admission to notification of OR did not significantly differ statistically between the two study groups (Table 2). However, the median time from notification of OR to AE was significantly shorter for the 2006-2009 group compared with the 2010-2011 group [3.6 (0.5-51.3) vs. 5.0 (0.5-33.6) h, $p=0.042$; Table 2].

The median times from ER admission to AE, ER admission to notification of OR, and notification of OR to $\mathrm{AE}$ in relation to the time of ER admission were further assessed (Table 4). For the subgroup of patients that arrived at the ER between 00:00 and 3:59 h, a significantly shorter overall in-hospital delay from OR-notification to AE was found for the 2006-2009 group than for the 2010-2011 group [6.6 (1.9-114.8) vs. $13.5(5.8-70.4) \mathrm{h}$, $p=0.022$; Table 4]. In addition, for the subgroup of patients that arrived at the ER between 20:00 and 3:59 h, significantly shorter delays from $\mathrm{OR}$ notification to $\mathrm{AE}$ were found for the 2006-2009 group than for the 2010-2011 group (Table 4). Moreover, for the patients that arrived at the ER between 12:00 and 15:59 h, a trend towards a shorter delay between ER admission and OR notification was found for the 2010-2011 group compared with the 2006-2009 group [3.5 (1.4-8.1) vs. 4.7 (0.6-33.5) h, $p=0.055$; Table 4].

\section{Discussion}

The present study has demonstrated that the restriction of nighttime AEs is feasible and safe with respect to rates of appendiceal perforation, infectious complications, and HLOS. However, after introduction of this new rule, the proportion of patients with an overall in-hospital delay of $>12 \mathrm{~h}$ increased significantly. Nevertheless, these results suggest that appendicitis can be managed safely in a semielective manner. Especially in view of increasing working hour limitations and tight health care budgets, this could optimize resource utilization.

At the University Hospital of Bern, AE is still the standard of care in patients with acute appendicitis. Although feasible, nonoperative management of uncomplicated appendicitis with antibiotics has been shown to have an overall inferior efficacy because of the high rate of recurrence compared with AE [12].

Several authors have shown that appendiceal perforation increases postoperative infectious morbidity and overall mortality [5-7]. Multiple risk factors for appendiceal perforation have been described in the past $[6,7]$. Older age, increasing WBC count and CRP level, as well as prehospital duration of abdominal pain are some of these risk factors that were confirmed in the current study. In contrast, large recent studies have suggested that the in-hospital delay to $\mathrm{AE}$ does not increase perforation rates or negatively impact the outcome of patient with acute appendicitis $[1,6,8-11,13]$. These findings suggest that appendiceal perforation occur before the patients arrive at the hospital. The current series supports this finding, because the prehospital duration of abdominal pain was independently associated with perforation, whereas the inhospital delay was not (Table 1).

On 1 January 2010, new guidelines (as described in the "Methods" section) were applied at Bern University 
Table 3 Comparison of the clinical outcomes and HLOS of the 2006-2009 and 2010-2011 groups

\begin{tabular}{|c|c|c|c|c|c|}
\hline & $\begin{array}{l}\text { Total } \\
(N=390)\end{array}$ & $\begin{array}{l}2006-2009 \text { group } \\
(N=255)\end{array}$ & $\begin{array}{l}2010-2011 \text { group } \\
(N=135)\end{array}$ & OR $(95 \% \mathrm{CI})$ & $p$ value* \\
\hline Mortality & 0 & 0 & 0 & - & - \\
\hline Perforated appendicitis [\% $(n)]$ & $19.5(76)$ & $20(51)$ & $18.5(25)$ & $0.91(0.53$ to 1.55$)$ & 0.725 \\
\hline Negative appendectomy $[\%(n)]$ & $5.4(21)$ & $5.9(15)$ & $4.4(6)$ & $0.74(0.28$ to 1.96$)$ & 0.549 \\
\hline Wound infection/dehiscence $[\%(n)]$ & $1.3(5)$ & $2(5)$ & $0(0)$ & 0.65 (0.6 to 0.7$)$ & 0.102 \\
\hline Abdominal abscess formation [\% $(n)]$ & $1.3(5)$ & $1.6(4)$ & $0.7(1)$ & $0.47(0.05$ to 4.23$)$ & 0.489 \\
\hline Postoperative ileus [\% $(n)]$ & $2.8(11)$ & $2.7(7)$ & $3(4)$ & $1.08(0.31$ to 3.76$)$ & 0.902 \\
\hline Postoperative sepsis $[\%(n)]$ & $0.8(3)$ & $0.8(2)$ & $0.7(1)$ & $\begin{array}{l}0.94(0.09 \text { to } 10.51) \\
\text { Mean difference }(95 \% \mathrm{CI})\end{array}$ & 0.963 \\
\hline HLOS (days) & $3.7 \pm 6.9$ & $3.9 \pm 7.4$ & $3.4 \pm 6$ & $-0.42(-1.94$ to 1.1$)$ & 0.586 \\
\hline
\end{tabular}

* Student's $t$ test, $\chi^{2}$ test

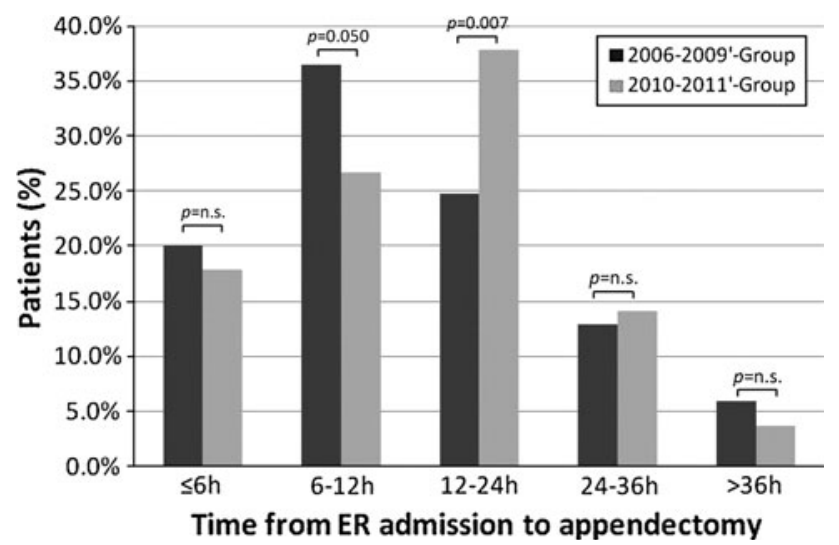

Fig. 1 Comparison between the study groups of the overall inhospital delay to appendectomy. ER emergency room, $n s$ not significant

Hospital to reduce the number of nighttime AEs. However, due to ethical concerns, the decision and timing of surgical intervention was at the discretion of the attending surgeon. Nevertheless, this intervention resulted in a significant decrease in nighttime AEs: from 46 to $19 \%(p<0.001)$. Before introduction of these guidelines, the number of AEs peaked shortly after midnight. After introduction of the new policy, the AEs shifted towards the late afternoon, with the surgical team on call during the night released.

Although many investigators have found correlations between in-hospital delay and outcomes, this does not permit any definitive conclusion about the necessity of nighttime AEs. Many variables might influence the inhospital delay to AE, such as the available diagnostic and OR capacity at different points in time. The present singleinstitution study permits the comparison of two similar groups of patients treated under different policies for nighttime AEs. In addition, very accurate times of ER admission, times of notification of the OR personnel by the responsible surgeon, and incision times were available for analysis. The time of notification of the OR personnel corresponds to the time required for the diagnosis and decision taken by the responsible surgeon. This diagnostic procedure is an essential part of the overall in-hospital delay and should be considered when it comes to in-hospital process improvement. To the best of our knowledge, there are currently no comparable studies available with similar data on diagnostic delay.

According to the present study, restriction of nighttime AEs by the new guidelines significantly increased the proportion of patients with an overall in-hospital delay of $>12 \mathrm{~h}$. However, the mean in-hospital delay relative to the time of ER admission was quite similar in the 2006-2009 and 2010-2011 groups. For the subgroup of patients that arrived at the ER between 00:00 and 03:59 h, the delay from OR notification to AE was significantly shorter for the 2006-2009 group than for the 2010-2011 group (Table 4). This group of patients arrived in the middle of the night and their operation was postponed until the next morning in accordance with the new guidelines, whereas under the previous rule, they would have been operated on immediately at night. Another interesting finding is that for patients who arrived at the ER between 12:00 and $15: 59 \mathrm{~h}$, there was a trend towards a shorter delay from ER admission to OR notification in the 2010-2011 group (Table 4). The new policy might have obliged the responsible surgical team on call to accelerate the diagnostic procedure to get the patient to the OR before 23:00 $\mathrm{h}$. This finding emphasizes the complexity and importance of the human factor when it comes to diagnostic delays and acceleration of in-hospital processes.

Another interesting finding is the fact that $19 \%$ ( $N=25$ ) of AEs within the 2010-2011 group were still performed between 23:00 and 08:00 $\mathrm{h}$. To further assess these "protocol violations," we compared the same characteristics and outcomes as shown in Tables 2 and 3 of these 25 patients with the remaining 110 patients in the 2010-2011 group. The only difference found was a 
Table 4 Comparisons of the delay from ER admission to appendectomy, ER admission to notification of OR, and notification of OR to appendectomy [h, median (range)] in relation to the time of ER admission

\begin{tabular}{|c|c|c|c|c|c|c|}
\hline ER admission time & Period of time & 2006-2009 group & $n$ & 2010-2011 group & $n$ & $p$ value* \\
\hline \multirow[t]{3}{*}{ 08:00-11:59 } & $\mathrm{ER}-\mathrm{AE}$ & $11.5(4-84.6)$ & \multirow[t]{3}{*}{52} & $12.5(4.5-37.4)$ & \multirow[t]{3}{*}{22} & 0.887 \\
\hline & ER-OR-notification & $5.8(1.5-80.9)$ & & $5.1(2.0-23.1)$ & & 0.897 \\
\hline & OR-notification-AE & $3.9(1.3-50.4)$ & & $4.4(1.1-33.6)$ & & 0.697 \\
\hline \multirow[t]{3}{*}{$12: 00-15: 59$} & $\mathrm{ER}-\mathrm{AE}$ & $10.7(3.1-35.5)$ & \multirow[t]{3}{*}{51} & $10.6(2.6-30.5)$ & \multirow[t]{3}{*}{25} & 0.472 \\
\hline & ER-OR-notification & $4.7(0.6-33.5)$ & & $3.5(1.4-8.1)$ & & 0.055 \\
\hline & OR-notification-AE & $3.5(1.4-30.1)$ & & $3.3(1.2-21.3)$ & & 0.933 \\
\hline \multirow[t]{3}{*}{ 16:00-19:59 } & $\mathrm{ER}-\mathrm{AE}$ & $10.2(0.8-44.5)$ & \multirow[t]{3}{*}{46} & $13.3(1.7-38.3)$ & \multirow[t]{3}{*}{27} & 0.945 \\
\hline & ER-OR-notification & $4.1(0.8-24.2)$ & & $4.1(0.3-30.7)$ & & 0.838 \\
\hline & OR-notification to $\mathrm{AE}$ & $4(1-27.4)$ & & $6.5(0.5-26)$ & & 0.775 \\
\hline \multirow[t]{3}{*}{$20: 00-23: 59$} & $\mathrm{ER}-\mathrm{AE}$ & $11.9(3.2-60.2)$ & \multirow[t]{3}{*}{57} & $14.9(5.6-30.3)$ & \multirow[t]{3}{*}{19} & 0.137 \\
\hline & ER-OR-notification & $3.8(1.1-26.4)$ & & $6.0(1.6-19.6)$ & & 0.944 \\
\hline & OR-notification-AE & $3.7(0.5-51.3)$ & & $6.9(1.1-21.1)$ & & 0.038 \\
\hline \multirow[t]{3}{*}{ 00:00-03:59 } & $\mathrm{ER}-\mathrm{AE}$ & $6.6(1.9-114.8)$ & \multirow[t]{3}{*}{31} & $13.5(5.8-70.4)$ & \multirow[t]{3}{*}{24} & 0.022 \\
\hline & ER-OR-notification & $3.7(0.5-105.2)$ & & $7.8(1.1-17.3)$ & & 0.638 \\
\hline & OR-notification-AE & $1.9(1.1-9.6)$ & & $4.2(1.9-26.8)$ & & 0.008 \\
\hline \multirow[t]{3}{*}{ 04:00-07:59 } & $\mathrm{ER}-\mathrm{AE}$ & $14.7(3.5-39.4)$ & \multirow[t]{3}{*}{19} & $11.7(4.5-29)$ & \multirow[t]{3}{*}{17} & 0.257 \\
\hline & ER-OR-notification & $9.1(1.4-29.2)$ & & $5.2(2.7-16.4)$ & & 0.148 \\
\hline & OR-notification-AE & $3.6(0.8-31.8)$ & & $5.2(1.1-26.1)$ & & 0.802 \\
\hline
\end{tabular}

$E R$ emergency room, $O R$ operating room, $A E$ appendectomy

*Mann-Whitney $U$ test

significantly longer overall in-hospital delay for the 25 patients operated during the night compared with the remaining 110 patients $(19.4 \pm 14.9$ vs. $13.9 \pm 8.4 \mathrm{~h}$, $p=0.013$ ). It seems that the surgical team on call wanted to get these patients to the OR to limit the in-hospital delay, which had already been extensive. It is striking that the rates of appendiceal perforation $(16 \%)$ and infectious complications $(4 \%)$ were not increased in these patients.

\section{Limitations}

The major limitations of the current study are its retrospective design and the relatively small number of patients. Due to ethical concerns, the data were analyzed after 2 years of observation with the new policy of no nighttime AE. By this, the sample size was given.

\section{Conclusions}

The present study demonstrates that in patients with acute appendicitis the restriction of AEs between 23:00 and 08:00 $\mathrm{h}$ does not increase appendiceal perforation rate and infectious complications. Therefore, we support the practice of treating acute appendicitis in a semielective manner to optimize hospital resource utilization.

\section{References}

1. Ingraham AM, Cohen ME, Bilimoria KY, Ko CY, Hall BL, Russell TR et al (2010) Effect of delay to operation on outcomes in adults with acute appendicitis. Arch Surg 145(9):886-892

2. Yardeni D, Hirschl RB, Drongowski RA, Teitelbaum DH, Geiger JD, Coran AG (2004) Delayed versus immediate surgery in acute appendicitis: do we need to operate during the night? J Pediatr Surg 39(3):464-469 (discussion 464-469)

3. Kearney D, Cahill RA, O'Brien E, Kirwan WO, Redmond HP (2008) Influence of delays on perforation risk in adults with acute appendicitis. Dis Colon Rectum 51(12):1823-1827

4. Abou-Nukta F, Bakhos C, Arroyo K, Koo Y, Martin J, Reinhold $\mathrm{R}$ et al (2006) Effects of delaying appendectomy for acute appendicitis for 12 to 24 hours. Arch Surg 141(5):504-506 (discussion 506-507)

5. Blomqvist PG, Andersson RE, Granath F, Lambe MP, Ekbom AR (2001) Mortality after appendectomy in Sweden, 1987-1996. Ann Surg 233(4):455-460

6. Teixeira PG, Sivrikoz E, Inaba K, Talving P, Lam L, Demetriades D (2012) Appendectomy timing: waiting until the next morning increases the risk of surgical site infections. Ann Surg 256(3):538-543

7. Busch M, Gutzwiller FS, Aellig S, Kuettel R, Metzger U, Zingg U (2011) In-hospital delay increases the risk of perforation in adults with appendicitis. World J Surg 35(7):1626-1633. doi:10. 1007/s00268-011-1101-z

8. Temple CL, Huchcroft SA, Temple WJ (1995) The natural history of appendicitis in adults. A prospective study. Ann Surg 221(3):278-281

9. Eldar S, Nash E, Sabo E, Matter I, Kunin J, Mogilner JG et al (1997) Delay of surgery in acute appendicitis. Am J Surg 173(3):194-198 
10. Hale DA, Jaques DP, Molloy M, Pearl RH, Schutt DC, d'Avis JC (1997) Appendectomy. Improving care through quality improvement. Arch Surg 132(2):153-157

11. Colson M, Skinner KA, Dunnington G (1997) High negative appendectomy rates are no longer acceptable. Am J Surg 174(6):723-726 (discussion 726-727)

12. Mason RJ, Moazzez A, Sohn H, Katkhouda N (2012) Metaanalysis of randomized trials comparing antibiotic therapy with appendectomy for acute uncomplicated (no abscess or phlegmon) appendicitis. Surg Infect 13(2):74-84

13. Ditillo MF, Dziura JD, Rabinovici R (2006) Is it safe to delay appendectomy in adults with acute appendicitis? Ann Surg 244(5):656-660 